\title{
A STUDY ON APPROPRIATENESS OF PERFORMANCE CRITERIA OF SMOKE CONTROL SYSTEM AMONG THE LOCAL FIRE SAFETY STANDARD FOR UNDERGROUND SPACES
}

\author{
C. AHN, H. KIM \& Y. YOO \\ Fire Research Centre, Korea Institute of Construction Technology, Republic of Korea.
}

\begin{abstract}
This study is intended to evaluate the characteristics of smoke spreading and the appropriateness of evacuation time extended by operation of smoke control system during fire within the underground space of the building structured in compliance with the smoke control system performance criteria from the local fire safety standard, which has been currently applied to the buildings in Korea. As a preceding review, the heat release of the combustibles was identified and based on outcome thereof; the type and specification of the combustibles existing at the possible fire location were examined, estimating the heat releases. In a bid to validate the estimated values, modeling a single underground shopping mall was carried out, and the combustibles examined during the preceding review was placed inside the building for a real scale fire test, the result of which was then reviewed and compared with a numerical analysis result. Using the heat release per unit weight of the combustibles, a numerical analysis both in case of smoke control system in operation and the system not in operation was carried out at several different shopping malls. From the viewpoint of securing the evacuation time, the results were compared in an attempt to assess the appropriateness of the fire safety criteria.
\end{abstract}

Keywords: Evacuation, smoke control, underground market.

\section{INTRODUCTION}

The underground space has been increasingly developed and the use has been diversified such as for stores, car parking and resting and cultural facilities. In line with such tendency, the number of users also has been on the rise [1]. Hence the criteria for smoke control system under the fire safety standard is yet to separate the rules for underground from the ground or above ground levels; but the same rule has been applied to, irrespective of the level.

Underground structure, in contrast to those on ground level, is highly enclosed, resulting in poor circulation of air between inside the building and outside, which requires ensuring the current fire safety rules specify sufficient evacuation time for the people when fire occurs as well as the appropriateness of the standards.

Prior to commencing the study, the examination to identify the fixed combustibles and movable combustibles occupying the internal space of the building was carried out, along with the measurement of heat release/unit weight of the raw material of those combustibles. To estimate the total heat release of the whole shopping mall area, a preliminary site survey to identify the entire structure of the shopping mall, location of each store, type of business, area and ceiling height was carried out and furthermore, the survey included the type, size, weight and raw material of the fixed combustibles such as office supplies, showcase and interior furniture. The examination for movable combustibles was also conducted to check the type, quantity, weight and raw material. Using the information on heat release per unit weight of the raw material, the heat release of combustible stuff available at the site was calculated. To prove the estimated heat releases of their own, modeling of the store randomly selected was carried out and the total heat release of the store, based on the values of 
combustibles at the store, was calculated on assumption of certain combustibles available in the store at all times.

Simulating the situation with the modeling stores, a fire test was conducted, along with the numerical analysis under the same condition and the outcome thereof was compared with the estimated heat release of the store.

In an effort to evaluate the appropriateness of the performance criteria of smoke control system under the domestic fire safety standard currently effective, a numerical analysis at 16 different shopping malls under the management of current fire safety rules was carried out, on assumption that the fire occurs while smoke control system is in operation and not in operation. The location and category of store, subject to numerical analysis, were arranged based on data obtained during site survey, and the fire load by type of business was estimated, referring to the information on combustibles, and the heat releases of the combustibles calculated based on values of raw material [2]. A fire was assumed to have been occurred near the center of the shopping mall, which was further expanded with the smoke spreading to the emergency exit [3]. Smoke spreading was analyzed based on two different scenarios; the first scenario was the case when a smoke control system was not operable so that the smoke was discharged through the exit only, and the second scenario was the case when a smoke control system was in operation, allowing the smoke to go out through both the exit and exhaust duct. The comparison was performed from the viewpoint of securing the evacuation time required [4].

\section{RESEARCH}

\subsection{Selection of shopping mall and examination of the combustibles}

The survey was carried out initially at 60 underground shopping malls in operation in six metropolitan cities, of which results were categorized by type and in the second stage, the shopping malls were grouped into the linear type and plaza type before finally selecting 16 large shopping malls to make it more comprehensive. The site survey was conducted at these 16 locations having 2,740 stores in total with 32 different types of business.

At the site survey, the total heat release of the stores was set as the value representing the combustion characteristics, and 1-3 stores were selected for sampling, making a total 70 samples, and the survey to check the combustibles available within the store was carried out. The survey classified the combustibles into the fixed ones and movable ones. The fixed combustibles included interior decoration, showcase and office supplies, while movable combustibles included the goods displayed for sale. As a result, total 953 combustibles were identified. The survey was aimed at identifying the type, raw material and weight of the combustible stuff, which served the basic data for estimating the heat release of each combustible.

\subsection{Measuring the heat release per unit weight of the raw material $(\mathrm{KJ} / \mathrm{Kg})$}

Totally 953 kinds of combustibles were checked as a result of site survey for measuring the heat release of the raw material, which were classified by type of raw material and consequently 49 types of raw material were determined, which are eight kinds of wooden material, three papers, nine textiles, 12 synthetic resins, 13 inorganic material and four composite materials. The heat releases per unit weight of those materials were measured in accordance with ISO 5660-1. 
2.3 Estimate of total heat release of the combustibles $(\mathrm{kJ})$

To estimate the unique heat release of the combustibles identified in the site survey, the heat release of the raw material measured was used. The unique heat release of each combustible was calculated multiplying the value of raw material by its total weight.

\subsection{A real scale fire test}

Modeling of randomly selected cloth stores was carried out for a real scale fire test and numerical analysis as indicated in Fig 1 and 2. A fire-rated gypsum board sized, $3,000 \times 3,000 \times 2,400 \mathrm{~mm}$ was used, and the front side of the store was left fully open. K-type thermocouples, six inside the left wall, 10 inside the ceiling and three in the internal space were arranged for monitoring the temperature. The fire was initially started at 2 locations on floor, one around the internal corner on the right side and another on the diagonally opposite side. A small amount of lamp oil soaked in cotton wool was used to set the fire. Total heat release, based on estimated value of the combustibles, was assumed to be about 2,500 GJ and in the inner space, two large wooden showcases, two steel coat hangers, a wooden desk and the computer, made of plastic material, were placed, and as the goods usually displayed, some clothes were put on a shelf, the hangers and the wall.

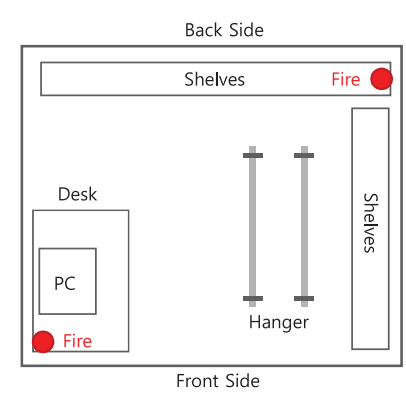

a. Top view

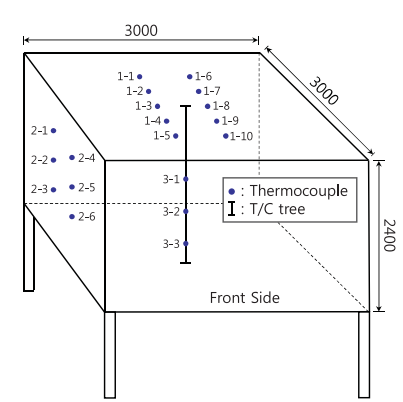

b. Thermocouple position

Figure 1: A real scale fire test model and thermocouples.

Table 1: Estimated heat release of the combustibles.

\begin{tabular}{lcccc}
\hline & Material & $\begin{array}{c}\text { Heat release } \\
(\mathrm{MJ} / \mathrm{kg})\end{array}$ & $\begin{array}{c}\text { Weight } \\
(\mathrm{kg})\end{array}$ & $\begin{array}{c}\text { Total heat release } \\
(\mathrm{MJ})\end{array}$ \\
\hline Table & Wood 1 & 10.9 & 10.5 & 114.45 \\
Showcase1 & Wood 2 & 13.9 & 31.3 & 435.38 \\
Showcase2 & Wood 2 & 13.9 & 31.3 & 435.38 \\
Computer & Plastic & 18.1 & 7 & 126.35 \\
Casual wear & Cotton & 22.4 & 63 & $1,411.20$ \\
\hline Estimated heat release of the store & & & $2,522.77$ \\
\hline
\end{tabular}




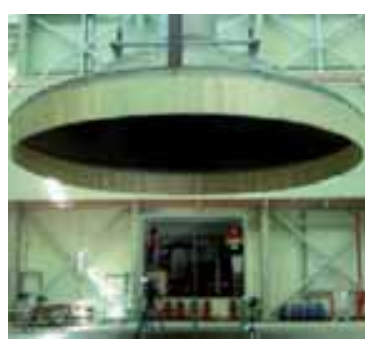

a. Store model

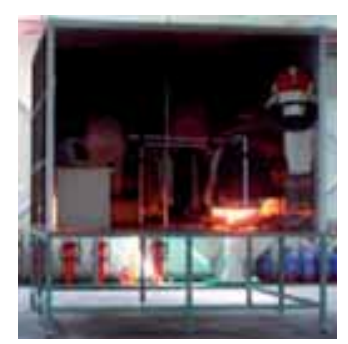

b. Fire setting

Figure 2: A real scale fire test.

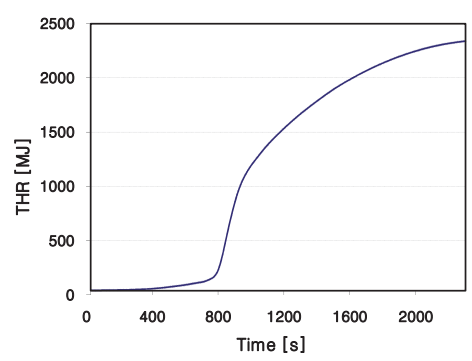

a. Total heat release

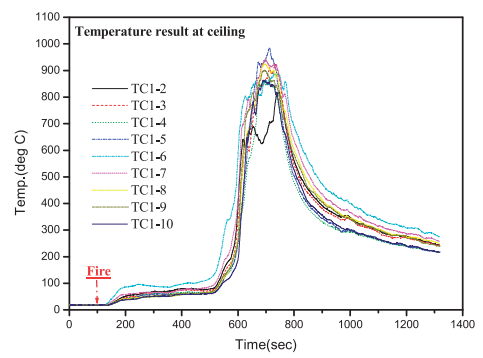

c. Ceiling temperature

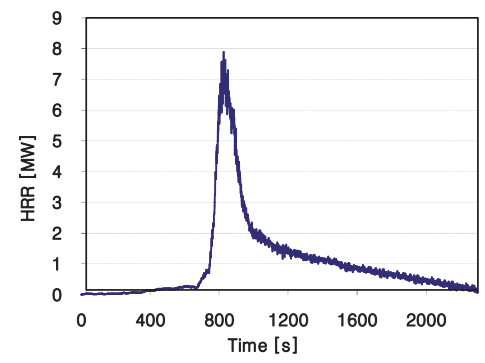

b. Heat release rate

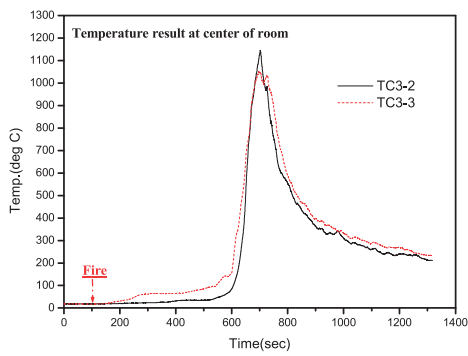

d. Internal temperature

Figure 3: Results of real scale fire test.

The fire continued for about 40 minutes; Fig. 3a indicates the total heat release. Fig. 3b indicates hourly discharged heat release. The fire gradually developed and eventually reached to flash point in 7 minutes, growing significantly and in 10 minutes it reached to the peak, indicating the maximum heat discharge before slowly reaching extinguishing. Total heat release was measured at 2,330 MJ with maximum hourly rate of 7,896 $\mathrm{kW}$. The temperature at the time of fire on the ceiling, the internal walls and inner space were monitored and was observed to have reached slightly more than $1,000^{\circ} \mathrm{C}$ (Fig. $3 \mathrm{c}, \mathrm{d}$ ).

\subsection{Numerical analysis}

A numerical analysis of the single store was conducted with a real scale model sized, $3,000 \times 3,000 \times 2,400 \mathrm{~mm}$ comprising with grids measuring $100 \times 100 \times 100$. Referring to the heat release of the raw material, wall, showcase, table, computer and the cloths were arranged 
to simulate the real store, and the fire was set at the two same locations as the real scale test. The positions of the thermocouples for measuring the temperature were arranged for the real scale test, 10 on ceiling, six on left side wall and three in the internal space. Fig. 4 shows the model before and after numerical analysis.

A calculation was done in an abnormal course and the analysis equivalent to 1,600 seconds simulation was carried out. As a result, the maximum heat-release rate was in the range 7.5 8MW section at 700 900 seconds, based on 800 seconds, and then stabilized at a constant value of $2 \mathrm{MW}$ sustained at 900-1,300 seconds. Fig. 5a indicates the total heat release from a single store, while Fig. $5 \mathrm{~b}$ represents heat release rate. The total heat release appeared to have reached to $2,300 \mathrm{MJ}$ at 1,300 seconds.

Heat is usually concentrated on ceiling surface in line with the growing flame inside the building and it indicated the higher temperature than other parts. The temperature mostly rose
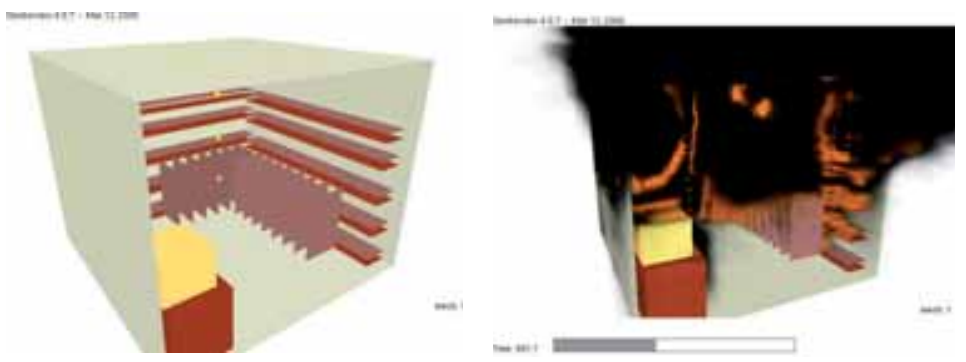

Figure 4: Numerical analysis model and combustion analysis.

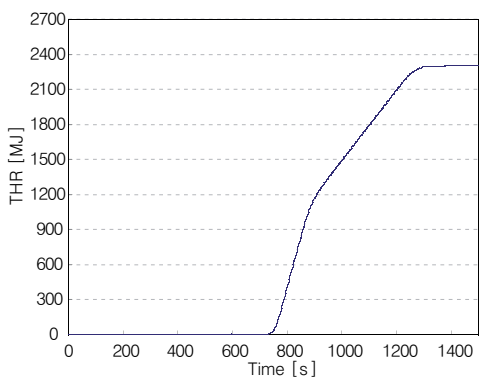

a. Total heat release

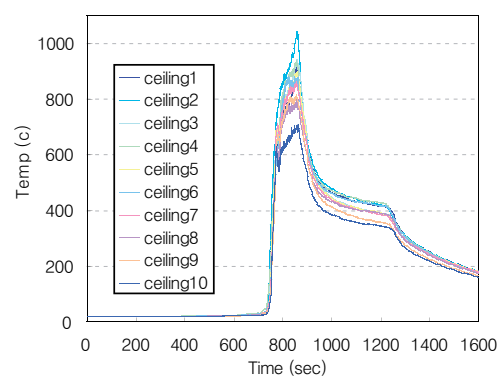

c. Ceiling temperature

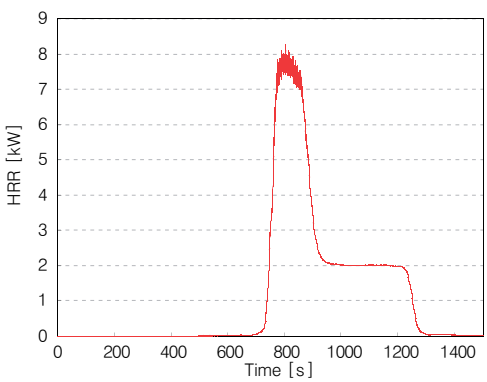

b. Heat release rate

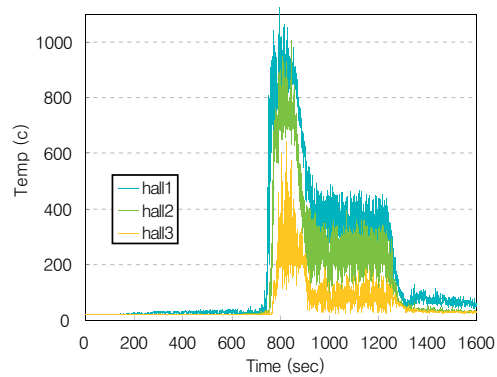

d. Internal temperature

Figure 5: Results of numerical analysis. 
to $700-800^{\circ} \mathrm{C}$, and in case of temperature measuring point $\# 2$, it reached to $1,100^{\circ} \mathrm{C}$. The temperature on left wall and inside the building indicated a range of $400-1,000^{\circ} \mathrm{C}$ (Fig. $\left.5 \mathrm{c}, \mathrm{d}\right)$

When comparing with a real scale test of single store, total heat release, heat release rate and temperature rising tendency appeared to be consistent, and when comparing with the total heat release estimated before the test, the error was within $8 \%$.

\subsection{Estimate of fire load by category of business $\left(\mathrm{kW} / \mathrm{m}^{2}\right)$}

The study of all the combustibles at all the 2,740 stores is practically unachievable; all 2,740 stores were grouped into 32 categories, and 1-3 stores per category were randomly selected, making the sample stores to 70 , and the site study of these stores was carried out to identify the quantity, size and weight of fixed and movable combustibles. Using heat release per unit weight of the raw material, total heat release and fire load of each store were calculated. 70 stores were grouped into 32 categories to calculate the average fire load of sample store of each category, and the value calculated was considered as the fire load representing the category which it belongs to.

\subsection{Performance criteria of smoke control system}

The performance criteria of smoke control system, for underground structure is not differentiated from those for the structure at or above ground level, by domestic fire safety standard, thus smoke exhaust and air supply performance should be in accordance with the common smoke control system. The air supply system may be either mechanical or a natural system, which has been generally adopted. Relevant regulation requires that the exhaust system should be the mechanical system. Thus the shopping mall area was divided into a number of smoke control zones and the capacity required was determined based on each zone.

Table 2 indicates the smoke control zones at 16 shopping malls, which were determined according to the domestic fire-safety standard, and the exhaust capacity required was estimated depending on each zone.

\subsection{Numerical analysis at the underground shopping malls}

To carry out the numerical analysis of 16 shopping malls, assuming to be filled with people, modeling of each shopping mall in a real scale, providing the same number of stores and area was conducted. Fig. 6 is one of the models for numerical analysis for the 16 shopping malls. The combustibles based on fire load of each category were brought to each store, and the outlet of smoke control system was provided on ceiling. The fire source was arranged at the center of the underground shopping mall so as to allow the flame and combustion gas to spread radially. The evacuation route was determined, calculating the short-cut to all exits. At $1 \mathrm{~m}$ interval along the evacuation route, smoke detectors were installed to calculate the time of spreading of the combustion gas. The smoke detectors were placed at $1.6 \mathrm{~m}$ above the floor so as to monitor the time taken till the evacuation route is blocked by the combustion gas coming down from the ceiling (Fig. 7)

The number of grids used for modeling is indicated in Table 2 and the grids were arranged in the shape of rectangle multi-block, which were calculated by parallel process using multi-processor.

A numerical analysis was conducted based on two cases, which were first, when smoke control system was not operable so that fresh air comes and combustion gas goes out naturally 
Table 2: Exhaust capacity and numerical grids of underground shopping malls.

\begin{tabular}{lrrrrrr}
\hline $\begin{array}{l}\text { Shopping } \\
\text { mall (SM) No }\end{array}$ & \multicolumn{1}{c}{$\begin{array}{c}\text { Area } \\
\left(\mathrm{m}^{2}\right)\end{array}$} & $\begin{array}{l}\text { No. of } \\
\text { store }\end{array}$ & $\begin{array}{l}\text { No. of } \\
\text { zone }\end{array}$ & $\begin{array}{r}\text { Exhaust } \\
\left(\mathrm{m}^{3} / \mathrm{hr}\right)\end{array}$ & $\begin{array}{r}\text { Total HR } \\
\left(\times 10^{6} \mathrm{~kJ}\right)\end{array}$ & $\begin{array}{r}\text { No. of grids } \\
\text { for analysis }\end{array}$ \\
\hline SM 1 & 977.2 & 32 & 1 & 50,000 & 903.61 & 347,760 \\
SM 2 & $2,310.7$ & 100 & 4 & 160,000 & 628.60 & 771,722 \\
SM 3 & $2,975.4$ & 97 & 3 & 130,000 & $2,096.77$ & 996,604 \\
SM 4 & $3,141.9$ & 64 & 2 & 100,000 & $1,554.10$ & $1,119,552$ \\
SM 5 & $3,676.3$ & 82 & 3 & 150,000 & $1,774.98$ & $1,213,632$ \\
SM 6 & $4,242.7$ & 59 & 3 & 150,000 & $1,353.78$ & $2,225,664$ \\
SM 7 & $4,566.8$ & 105 & 6 & 280,000 & $1,713.88$ & $1,549,464$ \\
SM 8 & $4,704.2$ & 113 & 5 & 230,000 & $2,177.31$ & $1,713,908$ \\
SM 9 & $7,080.3$ & 230 & 5 & 230,000 & $4,316.65$ & $2,455,600$ \\
SM 10 & $7,151.3$ & 218 & 6 & 295,000 & $6,206.83$ & $1,532,720$ \\
SM 11 & $7,640.1$ & 286 & 7 & 345,000 & $7,751.77$ & $3,007,648$ \\
SM 12 & $8,315.2$ & 162 & 6 & 300,000 & $2,352.32$ & $2,387,308$ \\
SM 13 & $8,830.7$ & 224 & 6 & 300,000 & $3,021.31$ & $3,248,546$ \\
SM 14 & $11,512.4$ & 192 & 6 & 350,000 & $2,633.69$ & $3,843,434$ \\
SM 15 & $12,234.5$ & 481 & 13 & 510,000 & $6,585.25$ & $6,095,096$ \\
SM 16 & $13,402.4$ & 295 & 10 & 500,000 & $13,346.14$ & $4,958,450$ \\
\hline
\end{tabular}

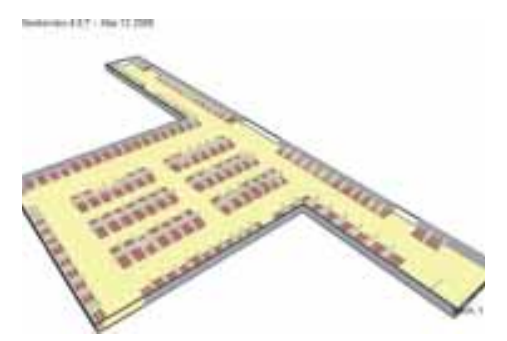

Figure 6: A real-scale modeling.

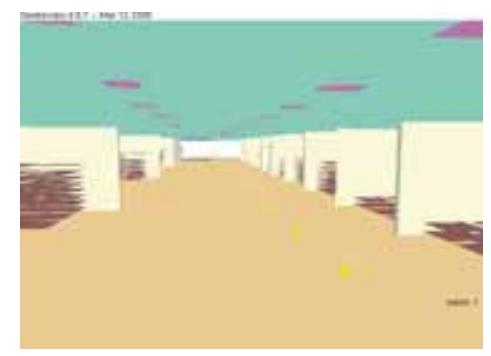

Figure 7: Outlet and detection sensor for combustion gas. 
through the exits only and second, when the smoke control system was in operation so that the circulation of both the air and combustion gas could be made, while combustion gas is removed by the mechanical exhaust through the outlet in ceiling.

\section{RESULT AND DISCUSSION}

In the wake of monitoring the variation of heat release rate in both cases, as indicated in Fig. 8, it appeared to have been significantly increased at all the 16 underground shopping malls because of the smoke control system in operation, which was attributable to more fresh air coming from the outside and mechanical exhaust of the combustion gas that aggravated the combustion. Fig. 9 is the example indicating the variation of spread speed of combustion gas at shopping mall \#8. Getting closer to the fire source, the difference tended to be getting smaller, indicating that the effect of smoke control system appeared to be decreased as it is getting closer to the fire source. As a result of monitoring the spread speed of combustion gas, no significant change was found, but when they were grouped to five categories, as shown in Table 3, the tendency in commonality by group was monitored. No effect of smoke control system appeared in Group 1, which means no evacuation time could be provided at all, while the effect to some extent could be expected in Group 2 and 3, but at the location within a certain distance, no sufficient time for evacuation could be expected. Hence, redesign of the smoke control system to enhance the effect will be needed for the shopping malls belonging to Groups 1, 2 and 3. However, no performance design is required for Group 5 as the current smoke control system provides sufficient evacuation time.

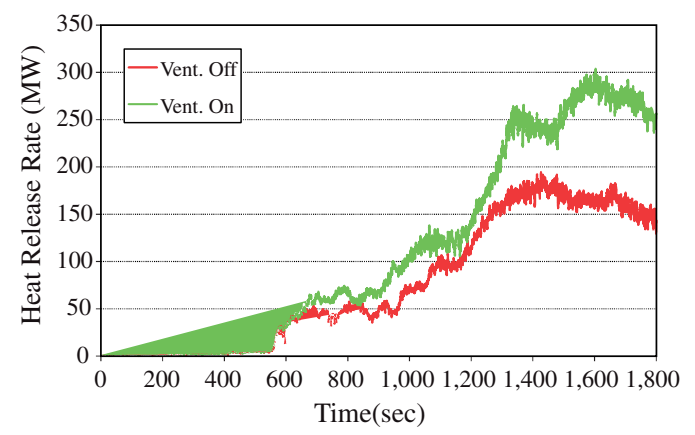

Figure 8: Variation of hourly rate of heat discharged.

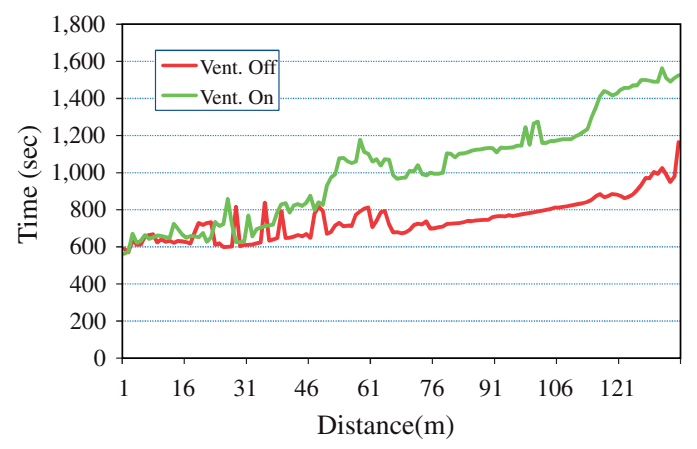

Figure 9: Variation of combustion gas detection time. 
Table 3: Effect of smoke control system.

\begin{tabular}{lccc}
\hline Group & $\begin{array}{c}\text { Effect to prevent combustion gas } \\
\text { from spreading (seconds) }\end{array}$ & Shopping mall \# & Number of stores \\
\hline Group 1 & None & $1,2,6,15$ & 4 \\
Group 2 & $0-100$ & $3,4,5,7,9,12,14$ & 7 \\
Group 3 & $100-200$ & $11,13,16$ & 3 \\
Group 4 & $200-300$ & & 0 \\
Group 5 & 300 & 8,10 & 2 \\
\hline
\end{tabular}

\section{CONCLUSION}

A numerical analysis was carried out using Fire Dynamics Simulator for the case when smoke control system was in operation and the ventilation system was not in operation during the fire, and the outcomes were compared from the standpoint of evacuation safety.

As indicated in the outcome, as a result of applying the same standard, without consideration of spatial characteristics of underground structure and the fire load of combustibles stored in the space, the effect of smoke control system designed to prevent the combustion gas from spreading at some shopping malls appeared to be unsatisfactory to a certain level. This clearly implies that the system may not be able to provide sufficient time required for safe evacuation of the people when the fire occurs in the underground structure, despite being controlled according to the current fire safety standard uniformly applied to all structures.

Thus, to be able to provide the time required for safe evacuation of the people in the underground building when fire occurs, the appropriate capacity of smoke control system should be calculated, taking into account the structural characteristics of the building and fire load and combustion characteristics of the combustibles stored, which shall be eventually incorporated into the design using performance design approach to finally determine the capacity to be provided.

Following this study, measuring the heat release per unit weight of various raw materials shall be carried out to produce more specific estimate of total heat release of the combustibles, and through the fire tests of diverse stores, the efforts to enhance the reliability of the values shall continue. Furthermore, the performance criteria of smoke control systems shall be established based on performance design approach, thereby identifying whether or not the time for safe evacuation could be provided.

This study was the outcome of the government R\&D project, "Development of smoke control/evacuation schemes and over 3-hour fire rated structural members in case of fire in large-space building" supported by the Korea Institute of Construction \& Transportation Technology Evaluation and Planning.

\section{REFERENCES}

[1] Lee, E.P., Analysis in the actual conditions of death due to fires based on annual report on the cause of death statistics in korea. KIESE, 20(1), p. 83, 2006.

[2] Chae, H.S., Suk, C.M., Kim, I.S., Lee, J.H. \& Kim W.J. Prediction of the fire behavior according to the fire load in an underground life space. KIESE, 21(1), pp. 51, 2007. 
[3] Cooper, L.Y., Smoke movement in rooms of fire involvement and adjacent spaces. Fire Safety Journal, 7(11), p. 33, 1984.

[4] Hwang, E.K., Kim, D.H., Cho, J.H. \& Hwang, K.S., A suggestions for building regulation through the analysis of problems among the building evacuation laws. KIESE, 21(4), p. $105,2007$.

This paper has been selected for this special issue but first appeared in WIT Transactions on the Built Environment, Vol 108, (c) 2009 WIT Press, www.witpress.com, ISSN 1743-3509 (on-line), doi:10.2495/SAFE090401. 